\title{
Retraction Note: Ocean surface circulation based on video features and swimmer training monitoring
}

\author{
Zhang Yanchao ${ }^{1} \cdot$ Lan Kaihui $^{2} \cdot$ Lv You $^{3}$
}

Published online: 12 November 2021

(c) Saudi Society for Geosciences 2021

\section{Retraction Note: Arabian Journal of Geosciences (2021) 14: 1593}

https://doi.org/10.1007/s12517-021-07932-4

The Editor-in-Chief and the Publisher have retracted this article because the content of this article is nonsensical. The peer review process was not carried out in accordance with the Publisher's peer review policy. The authors have not responded to correspondence regarding this retraction.

The original article can be found online at https://doi.org/10.1007/ s12517-021-07932-4.

Lv You

1 Physical Education Department of Guangxi, University of Finance and Economics, Nanning 530003, China

2 Public Teaching Department of Quanzhou Preschool Normal College, Quanzhou 362000, China

3 College of Physical Education and Health of Nanning Normal University, Nanning 530299, China 